\title{
A dualidade na faculdade imaginativa em Descartes*
}

\author{
Lucas Guerrezi Derze Marques*
}

\begin{abstract}
Resumo: Pretendo demonstrar neste artigo como a faculdade imaginativa pode ser ambiguamente tratada nas obras cartesianas. A partir de uma análise de suas obras metafísicas e matemáticas, notaremos uma grande diferença no tratamento dessa complexa faculdade. É de fácil percepção que a faculdade imaginativa em suas obras metafísicas não possui um destaque positivo para essa ciência. Uma das características da imaginação é a dependência do uso de imagens em seu modo de pensamento. Isso é suficiente para sua exclusão no estudo dessa ciência do intelecto puro. Deixando assim, a imaginação em suas obras metafísicas, apenas como um instrumento de sua dúvida metódica, e talvez como algum indício para um argumento da realidade de nosso próprio corpo. Divergentemente, tal modo de pensamento, desenvolvido em suas ciências matemáticas, não somente utilizam rigorosamente dessa faculdade, como são dependentes dela, vemos na geometria.
\end{abstract}

Palavras-chave: Imaginação. Imaginação produtiva. Res extensa. Res cogitans. Sensação.

\section{La dualité dans la faculté imaginative chez Descartes}

Resumé: J'ai l'intention de démontrer dans cet article comment la faculté imaginative peut être traitée de manière ambiguë dans les œuvres cartésiennes. A partir d'une analyse de ses travaux métaphysiques et mathématiques, on remarquera une grande différence dans le traitement de cette faculté complexe. Il est facile de s'apercevoir que la faculté d'imagination dans ses travaux métaphysiques ne constitue pas un élément positif pour cette science. L'une des caractéristiques de l'imagination est la dépendance à l'égard de l'utilisation des images dans leur façon de penser. Cela suffit pour son exclusion dans l'étude de cette science de l'intellect pur. Laissant ainsi l'imagination dans ses œuvres métaphysiques, seulement comme instrument de son doute méthodique, et peut-être comme indice d'un argument de la réalité de notre propre corps. De manière divergente, un tel mode de pensée, développé dans ses sciences mathématiques, utilise non seulement cette faculté de manière rigoureuse, car ils endépendent, nous le voyon sen géométrie.

Mots-Clé: Imagination. Imagination Productive. Res extensa. Res cogitans. Sensation.

\section{Introdução}

Pretendo neste texto demonstrar o modo pelo qual a faculdade imaginativa foi ambiguamente tratada nas obras cartesianas. A partir de uma análise dos pensamentos metafísico e científico/matemático de Descartes, esperamos evidenciar as grandes diferenças no tratamento

\footnotetext{
* Artigo produzido com auxílio da FAPEMIG e sob a orientação do Prof. Dr. Sertório de Amorim e Silva Neto, Professor Adjunto do Instituto de Filosofia da Universidade Federal de Uberlândia, onde atua também como Coordenador do Programa de Pós-Graduação em Filosofia.

* Graduando em Filosofia pelo Instituto de Filosofia da Universidade Federal de Uberlândia (IFILO-UFU). Bolsista de Iniciação Científica FAPEMIG. E-mail: lucasguerrezi@ hotmail.com.
} 
dessa complexa faculdade. É de fácil percepção que a faculdade imaginativa não adquire, para ele, um destaque muito positivo em se tratando da metafísica, ciência dedicada ao estudo da imaterialidade de Deus e da alma humana. Diversamente do que se observa na metafísica, no campo das matemáticas a imaginação mereceria uma outra atenção do nosso filósofo, já que de seu uso rigoroso dependeria a geometria.

A pouca consideração dedicada especificamente ao tema da imaginação em Descartes chama, também, a atenção, já que ele nos oferece, como mostram alguns estudiosos ${ }^{1}$, um caminho a ser seguido para a investigação da sua Física, que é amplamente dependente das figuras, suposições e hipóteses, do uso das analogias e das máquinas, que, por sua vez, pressupõem uma certa atuação da faculdade de imaginar ${ }^{2}$.Devido a uma consolidada tradição de estudos mais atenta à metafísica que a outros aspectos da obra cartesiana, tornou-se comum encarar a imaginação e os conhecimentos adquiridos através dessa faculdade como inválidos, quase exclusivamente fontes de erros. De certo modo, os próprios estudos sobre Descartes evidenciam essa ambiguidade no tratamento da faculdade imaginativa na sua vasta obra: um papel secundário e praticamente descartável para sua metafísica; um papel não só importante, mas fundamental para os estudos que envolvam a extensão, como a Física e também a geometria.

\section{Imaginação e Metafísica}

É de suma importância discutirmos os conceitos de corpo, res extensa, e de mente, res cogitans, as distinções e as ligações que lhes são inerentes para alcançarmos a justa compreensão da noção cartesiana da faculdade de imaginar, pois ela é um tipo específico de pensamento que se serve tanto da mente como do corpo para criar suas representações. $\mathrm{O}$ famoso dualismo cartesiano - fazemos notar - dá o ponta pé inicial para essa investigação ${ }^{3}$.

${ }^{1}$ Cf. GUENANCIA, Pierre. L'Intelligence du sensible. Essai sur le dualisme cartésien. Paris: Gallimard, 1998. 384 p.

${ }^{2}$ Cf. DESCARTES, René. O mundo (ou tratado da Luz) / René Descartes; apresentação, apêndices, tradução e notas: Marisa Carneiro de Oliveira Franco Donatelli. - Campinas, SP: Editora da Unicamp, 2009. E principalmente os ensaios que acompanhavam originalmente o Discurso, ou seja, A Dióptrica, Os Meteoros e A Geometria em: DESCARTES René. Discurso do método e Ensaios/ René Descartes; organizado por Pablo Rubén Mariconda; traduzido por César Augusto Battisti, Érico Andrade, Guilherme Rodrigues Neto, Marisa Carneiro de Oliveira Franco Donatelli, Pablo Rubén Mariconda, Paulo Tadeu da Silva. - São Paulo: Editora Unesp, 2018. Nestes ensaios, encontramos alguns dos principais escritos de Descartes sobra a física mecanicista e a geometria. Podemos observar o quão importantes eram para ele seus desenhos, hipóteses e suposições, numa ciência dedicada a res extensa.

${ }^{3}$ No livro A Imaginação, Jean-Paul Sartre notou que durante a filosofia medieval prevaleceu uma teoria dualista do homem dividido em uma parte semi-material e a outra semi-espiritual, contudo, teria sido Descartes o responsável por precisar essa distinção (Cf. SARTE, Jean-Paul. A Imaginação. Tradução brasileira de Luiz Roberto salinas Fortes. São Paulo: Difusão Europeia do Livro, 1967, p. 11-13). 
A mente, o pensamento, a alma ou espírito são designados por Descartes com um significado, o da res cogitans (coisa pensante): "uma substância cuja essência ou natureza consiste apenas no pensar [...] E embora talvez eu tenha um corpo a que estou ligado de modo muito estreito [...] minha alma, pela qual sou o que sou, eu sou deveras distinto do corpo e posso existir sem ele.”(DESCARTES, 2004, p. 169). No curso de suas meditações metafísicas Descartes se descobre coisa que pensa e existe: "Sou [...] uma coisa verdadeira e verdadeiramente existente. Mas, qual coisa? [...] coisa pensante. E, que mais?" (DESCARTES, 2004, p. 49). Não saberei o que mais? Mas o que é enfim essa res cogitans? Para precisá-la, uma coisa, porém, Descartes sabe com toda a certeza: a imaginação em nada pode contribuir diretamente com essa tarefa. Para ele, a substância pensante tem o atributo essencial da imaterialidade, e define-se, por isso, por distinção do que é material e corpóreo, enquanto a imaginação - explica Descartes - "é uma maneira de pensar particular às coisas materiais" (DESCARTES, 1999a, p. 66), aplicável, portanto, aos corpos, na física e inclusive nas artes, mas que nada pode nos dizer sobre as realidades metafísicas, sobre Deus e a alma. Ao pesquisarmos essa faculdade nas obras metafísicas de Descartes, principalmente em suas famosas Meditações, perceberemos que a imaginação vem geralmente tratada, pelo autor, com uma certa negatividade: por causa de suas características fundamentais, ela seria uma forma de pensar inadequada para conhecimentos puros, como os metafísicos, causando mais estorvos do que ganhos.

A principal definição de imaginação encontrada nas obras cartesianas é de uma faculdade capaz de conceber imagens. A imaginação se constitui quando a mente, na esperança de presenciar algo, cria e imprime imagens no cérebro, mais precisamente na glândula pineal, por ação da própria mente e sem o vislumbre de qualquer sensação atual. Isto é, por meio da imaginação pensamos imagens no cérebro, tal como elas ocorrem nas sensações, mas sem a necessidade da presença dos objetos exteriores, aos quais essas imagens correspondem. O pensamento por imagens, nesse caso, não é simplesmente passivo, como no caso das sensações, onde sofremos a ação dos objetos que nos afetam, e sim ativo. Descartes assim a descreve no $20^{\circ}$ Art. das Paixões da Alma:

Quando a alma se põe a imaginar algo que não existe, como a fantasiar um palácio encantado ou uma quimera[...] as percepções que tem dessas coisas dependem principalmente da vontade que a leva a percebê-las; é por isso que se costuma considerá-las ações mais do que paixões. (DESCARTES, 1999a, p. 119).

Diferente da imaginação, que é uma ação da alma, as sensações são puras paixões.

Nelas, as imagens dos objetos exteriores são percebidas pela alma independentemente de sua 
vontade, mas constrangida pelo contato físico deles com os nossos órgãos sensitivos: "são causadas [...] por esses objetos que, provocando alguns movimentos nos órgãos dos sentidos externos, os provocam também no cérebro por intermédio dos nervos, os quais levam a alma a senti-los”(DESCARTES, 1999a, p. 119). São os nervos os encarregados de transmitir os movimentos dos objetos que afetam os nossos órgãos sensitivos até a alma, fazendo com que os perceba e tenha as ideias correspondentes. Assim, a alma entra em contato com os objetos exteriores somente indiretamente, ou através dos movimentos causados pelos nervos nela própria. Tais percepções, "que atribuímos a coisas que se encontram fora de nós, aos objetos de nossos sentidos", descreveu Descartes no $23^{\circ}$ Art. das Paixões da Alma,

são causadas, ao menos quando nossa opinião não é falsa, por esses objetos que, ao ocasionar alguns movimentos nos órgãos dos sentidos externos, os ocasionaram também no cérebro mediante os nervos, os quais fazem com que a alma os sinta. (DESCARTES, 1999a, p. 119).

Deste modo, notamos que o estatuto da sensação é a passividade, ou seja, a alma não possui tarefa alguma nesse tipo de pensamento, exceto perceber. Em suma, as sensações, são transmitidas pelo nosso corpo até nossa alma, em uma espécie de cadeia de transmissão. ${ }^{4}$

Já a imaginação é considerada uma faculdade ativa, pois possui a capacidade de proporcionar imagens, ou melhor, materialidade, aos pensamentos. E essa é uma capacidade da alma, apesar de ela, nisso, depender do corpo e da extensão. Diferentemente da sensação, que possibilita à alma perceber as coisas sensíveis pelo contato indireto com elas, atualmente, a imaginação pode ser produzida sem a presença do objeto material exterior. Através da ação/vontade da alma, nossa capacidade imaginativa pode lembrar de alguma sensação, ou até mesmo criar uma nova, a partir da composição ou decomposição das memórias ${ }^{5}$. Uma ótima exposição do problema está na troca de correspondências entre Descartes e Frans Burman:

\footnotetext{
Quando os objetos exteriores atuam sobre os meus sentidos, imprimem neles uma ideia, ou antes, a imagem deles mesmos. E quando a mente se debruça sobre essas imagens gravadas na glândula (isto é, na glândula pineal) é desta forma que se produz a percepção sensorial (sentire). Quando, por outro lado, as imagens são gravadas na glândula, não por objetos exteriores, mas pela própria mente, que os
}

\footnotetext{
${ }^{4}$ Cf. $1^{\circ}$ nota do tradutor, DESCARTES, René. Paixões da alma. Tradução brasileira de J Guinsburg. São Paulo: Editora Nova Cultural, 1996. Para Descartes a descoberta e sistematização do sistema circulatório pelo médico william Harvey foi de extrema importância para sua teorização dos espíritos animais como encarregados das transmissões sensitivas. Através destes espíritos que as sensações são transmitidas para a alma, ou, que a alma transmite seus comandos para o corpo.

5

Cf. COTTINGHAN, Jhon. Dicionário Descartes; tradução, Helena Martins; revisão técnica, Ethel Alvarenga; consultoria, Raul Landim - Rio de Janeiro: Jorge Zahar Ed., 1995. Ver os verbetes: "Imaginação", "Sensação" e "Ser humano". O autor relata com precisão a diferença das duas faculdades, imaginação e sensação, do intelecto puro.
} 
molda e os forma no cérebro na ausência de objetos então dá-se a imaginação. A diferença entre a percepção sensorial e a imaginação é realmente apenas esta, de que na percepção sensorial as imagens são gravadas no cérebro pelos objetos exteriores que estão realmente presentes, enquanto que no caso da imaginação as imagens são gravadas pela mente sem quaisquer objetos exteriores e com as janelas fechadas, por assim dizer (DESCARTES, 1903, p. 162-163.)

No final da quarta parte do Discurso do método, bem como na Segunda Meditação, a imaginação é apresentada por Descartes como estando vinculada à natureza corpórea e, deste modo, incapaz de servir à metafísica. Ela aparece, ali, fundamentalmente, como faculdade imagética e, por isso, limitada a pensar as coisas em função daquilo que Descartes definiu como "res extensa", isto é, a extensão, a figura e suas dimensões. O filósofo francês nota que "imaginar não é senão contemplar a figura ou a imagem de uma coisa corporal" (DESCARTES, 2004, p. 51), concluindo, então, que os seres incorporais, sem imagem ou figura, não podem absolutamente e não devem ser imaginados, sob o risco de adulteração e do erro.

Sobre a res cogitans, lemos nas Meditações: "de sorte que reconheço que nada do que posso compreender com a ajuda da imaginação pertence ao conhecimento que tenho de mim." (Idem.). Portanto, a faculdade de imaginar aparece nas reflexões metafísicas de Descartes, por um lado, por contraste, como um meio de definir o justo caminho das meditações metafísicas, puras e abstratas, obtidas a partir de ideias que são inatas, mas aparece, também, como um vício a ser evitado, como faculdade apta a nos fazer errar: dar corpo à alma e figura a Deus.

Sobre esse aspecto, a imaginação em primeira pessoa - a de Descartes - atua como instrumento fundamental da dúvida hiperbólica, projetando dúvidas sobre as opiniões comumente aceitas pelos filósofos acerca da natureza humana e em especial sobre a natureza da alma, servindo como um meio de definir o justo caminho das meditações metafísicas.

\footnotetext{
Ocorria-me [...] que me alimentava, andava, sentia e pensava, ações que eu referia por certo a uma alma. Mas, o que essa alma era, ou não o notava ou, se me detinha em considerá-lo, imaginava [ele, Descartes]um não sei que de diminuto, a exemplo do vento ou do fogo ou de um éter, infuso em minhas partes mais espessas. (DESCARTES, 2004, p. 46-47).
}

Se nos atentarmos para as duas primeiras Meditações, percebemos que a faculdade imaginativa possui uma importante tarefa na definição de res cogitans. Para definir o que é uma coisa que pensa, ele utiliza, a todo momento, como contraditório, aquilo que pode ser imaginado. Descartes sempre estimula sua imaginação para tentar encontrar o que ele realmente era além de uma coisa pensante, que no momento ainda era somente aquilo que 
conseguia dizer com certeza. Mas, todas as alternativas que a imaginação lhe oferecia eram tidas como dubitáveis, assim como todo o corpo, e Descartes foi construindo seu conceito de res cogitans a partir do que não era res extensa, pois, a imaginação só constrói pensamentos a partir da extensão. Como a imaginação só lhe oferecia pensamentos sobre a materialidade, e o que ele buscava era a imaterialidade, ou seja, o pensamento puro, a alma, Descartes fez da imaginação, portanto, um instrumento de sua dúvida. "Sou, porém, uma coisa verdadeira e verdadeiramente existente. Mas, qual coisa? Já disse: coisa pensante. E, que mais? Usarei minha imaginação para ver se não sou algo mais.” (DESCARTES, 2004, p.49). Porém, a partir desse trecho, Descartes já estabelece um limite para a imaginação na tentativa de conceituar o „Eu ${ }^{\text {ee }}$ pensante, pois imaginar nada mais é do que dar limite e extensão, figura e imagem, de coisa corporal, ao pensamento. E nega completamente a existência de extensão e matéria em nossa res cogitans.

A imaginação desempenharia um importante papel na dúvida metódica e hiperbólica das Meditações. No terceiro e último passo da dúvida cartesiana - relativo ao gênio maligno ou deus enganador - essa faculdade é novamente evocada, agora como uma criadora de hipóteses. Desde que Descartes inicia seu argumento fica evidente a utilização da faculdade imaginativa, já que tal "gênio" não passa, para ele, de uma hipótese ou suposição:

Suporei, portanto, que há não um Deus ótimo, fonte soberana da verdade, mas algum gênio maligno e, ao mesmo tempo, sumamente poderoso e manhoso, que põe toda a sua indústria em que me engane (DESCARTES, 2004, p. 31 - grifo meu).

Com o argumento do gênio maligno o autor se serve da imaginação para levar o método de investigação ao seu nível máximo: a ponto de pôr em dúvida as verdades matemáticas, que até então eram aceitas sumamente evidentes. A imaginação de um Deus enganador dá à mente a ocasião para suspeitar das matemáticas, reafirmando seu lugar de destaque no corpo da dúvida metódica:

Ora, quando, acerca das coisas aritméticas e geométricas eu considerava algo muito simples e fácil [...] E por certo que, se depois julguei que elas podiam ser postas em dúvida, não foi por outra causa senão por me vir a mente que algum Deus podia me haver dado uma natureza tal que eu fosse enganado também acerca das coisas que me pareceriam as mais manifestas. (DESCARTES, 2004, p. 73 - grifos meus). 
O uso das hipóteses, cuja importância Descartes havia já reconhecido em relação à Mathesis Universalis e à geometrização, às quais servem como enxertos a preencherem lacunas nos dados sensíveis disponíveis, acabaria sendo expandido também à Metafísica ${ }^{6}$.

Deste modo, apesar de toda uma repulsa à imaginação enquanto se trata de assuntos metafísicos, ela ainda ocuparia um papel importante na argumentação cartesiana. Ainda no contexto da Segunda Meditação vemos o filósofo admitir que: "Mas, em verdade, eu também sou o mesmo que imagina, pois, ainda, que, segundo supus, nenhuma coisa imaginada seja verdadeira, a própria força de imaginar, todavia, existe deveras e faz parte de meu pensamento" (DESCARTES, 2004, p. 53). A imaginação, portanto, teria algo a dizer sobre a nossa natureza humana e sobre aquela do nosso pensamento, revelando um lugar privilegiado na argumentação metafísica. Grosso modo, a faculdade de imaginar demonstra que a res cogitans - e ainda que não possa ser "de modo algum tirada do poder da matéria" - está “junta e unida com ele [o corpo humano] para ter [...] sentimentos e apetites semelhantes aos nossos, e assim compor um verdadeiro homem" (DESCARTES, 1999a, p. 84).

Nosso corpo está estreitamente ligado ao „Eu pensante’ de forma quase intrínseca, apesar de cada um possuir um valor ontológico totalmente distinto do outro: um divisível e corruptível, o outro indivisível e imortal por sua natureza. Essa união "quase intrínseca" gera seus frutos. Descartes, deixa claro que existem faculdades ou modos de pensar que se distinguem daquele do „Eu pensante’ não corporal, ou seja, da alma, e tais faculdades são a imaginação e a sensação. Assim diz Descartes em sua Sexta meditação:

\begin{abstract}
Acrescento que essa força de imaginar que está em mim [...] não é algo requerido por mim mesmo, isto é, pela essência de minha mente. Pois, mesmo que estivesse ausente de mim, eu sem dúvida, permaneceria o mesmo que agora sou. De onde parece seguir-se que ela depende de alguma coisa diversa de mim." (DESCARTES, 2004, p. 159)
\end{abstract}

ou seja, do corpo. Em suma, essas duas faculdades, imaginação e sensação, são ditas, portanto, psicofísicas. Eis um ponto complicado da filosofia cartesiana, pois tudo o que Descartes tinha revelado, até o momento, foram os atributos de duas espécies, ou mentais, da alma, ou físicos, do corpo. John Cottingham chama tais faculdades de "híbridas"”.

\footnotetext{
6 Segundo Érico Andrade "O recurso a suposições não implica que certas demonstrações sejam a priori destituídas de verdade, mas, pelo contrário, ele possibilita a constituição de um conhecimento certo daquilo que não se apresenta imediatamente como evidente". (ANDRADE, Érico. 2006, p. 267).

${ }^{7}$ Cf. COTTINGHAN, Jhon. Dicionário Descartes; tradução, Helena Martins; revisão técnica, Ethel Alvarenga; consultoria, Raul Landim - Rio de Janeiro: Jorge Zahar Ed., 1995. Ver os verbetes: "Imaginação", "Sensação" e "Ser humano". O autor relata com precisão a diferença das duas faculdades, imaginação e sensação, do intelecto puro.
} 
Descartes coloca a sensação, mas também a imaginação como modos especiais de pensamento, pois, apesar de serem "pensamentos", exigem atividade fisiológicas do corpo. Segundo ele, no artigo 43 das Paixões da alma: "Quando se deseja imaginar alguma coisa [...] essa vontade tem o poder de levar a glândula a mover-se da maneira necessária para impulsionar os espíritos para os poros do cérebro por cuja abertura essa coisa pode ser representada" (DESCARTES, 1999a, p. 131.). Isso gera inúmeras complicações na teoria, pois, como já notamos, a res cogitans e a res extensa possuem significações bem distintas, sugerindo a impossibilidade de uma ligação entre elas. Uma e outra recebem suas definições pela distinção uma da outra: "suas naturezas são por nós conhecidas não apenas como diversas, mas, de certo modo, como contrárias também" (DESCARTES, 2004, p. 37). Para resolver o problema, Descartes recorre ao argumento da glândula pineal, encontrada no cérebro e local de ocorrência desse encontro.

$\mathrm{O}$ ato de imaginar se constitui quando a mente, na esperança de presenciar algo, cria, imprime imagens em nosso cérebro, por ação da própria mente e sem o vislumbre de qualquer sensação atual. E essa fecundidade da imaginação é virtude mesma da sua natureza híbrida. Ela é a faculdade humana capaz de criar imagens de coisas extensas sem tê-las em nossa presença. E é isso que gera a desconfiança de Descartes em relação a essa faculdade: a imaginação apresenta ao cérebro coisas que não são necessariamente reais, que são só possíveis, ficções. Um ser mitológico imaginado não é necessariamente algo real, ainda que o cérebro o perceba como tal. A imaginação revela também outros limites cognitivos que levaram Descartes a separá-la do intelecto puro, negando-lhe a clareza e distinção indispensáveis à Metafísica. Ele explica o caso dando-nos o exemplo da figura geométrica do Polígono regular de mil lados, o quiliógono:

\footnotetext{
[...] quando imagino um triângulo, por exemplo, não só entendo que se trata de uma figura compreendida por três linhas, mas, ao mesmo tempo, vejo também essas linhas como estando presentes ao olhar da mente, e é isto o que chamo de imaginar. Se quero, agora, pensar em um quiliógono, entendo na verdade que se trata de uma figura constante de mil lados tanto quanto entendo que o triângulo consta três. Mas não imagino esses mil lados do mesmo modo, isto é, não os vejo como que presentes com os olhos de minha mente, não consigo por assim dizer, que estejam como que presente. (DESCARTES, 2004, p. 157)
}

Vemos, a partir deste trecho da Sexta Meditação, os limites da imaginação para o exame preciso dos objetos do entendimento. Ela está presa à capacidade figurativa e, na medida em que o grau de dificuldade dos objetos em exame se eleva, ela vai se tornando cada vez mais falha e dubitável, diferentemente do intelecto puro. Isto se deve ao fato de a 
imaginação ser faculdade híbrida e depender da res extensa, da natureza corpórea, ou pelo número ilimitado de efeitos físicos que precisamos provocar no cérebro e para formarmos a imagem de um quiliógono. A possiblidade de concebê-lo, nesse caso, não acompanha aquela de tornar sua figura presente por força de imaginação.

Essa limitação do ato de imaginar também possui um grande valor argumentativo na metafísica cartesiana, pois, ao tentarmos imaginar alguma coisa, não estamos praticando atos puramente intelectuais e sim um ato que depende intimamente do nosso corpo para ser efetuado, o que confirma, no fundo, a existência do meu corpo próprio. No contexto da argumentação cartesiana sobre a imaginação, que evidência, pouco a pouco, que algum corpo existe ao qual meu espírito esteja conjugado e unido a res cogitans se despede de uma substancialidade isolada para formar, com o corpo, o homem, uma unidade substancial. Como nos fez ver Martial Gueroult:

[...] o esforço requerido pela imaginação parece bem envolver que o espírito aí se aplique a alguma coisa que lhe seja estranha e lhe resista, em resumo: algo que não poderia ser senão o corpo. Eu poderia, então, concluir daí que o corpo existe. Como, por outro lado, a alma pode aplicar-se, quando lhe apraz, a esse corpo para materializar seus conceitos, parece que se pode concluir daí igualmente que ela lhe é estreitamente unida e conjunta: conceber-se-ia então que, na pura intelecção, a alma se voltaria para ela mesma para considerar as ideias que ela guarda em seu interior, ao passo que, na imaginação, voltar-se-ia para seu corpo (o cérebro) para contemplar a ideia que ela mesma nele grava e que ela tem de seu intelecto. A imaginação testemunharia então que o corpo existe e que minha alma está unida a um corpo. (GUEROULT, 2016, p. 486-487).

Se formos buscar uma resposta fisiológica para o ato de imaginar, encontraremos na obra Paixões da alma a seguinte explicação:

Quando se deseja imaginar alguma coisa jamais vista, essa vontade tem o poder de levar a glândula a mover-se da maneira necessária para impulsionar os espíritos para os poros do cérebro por cuja abertura essa coisa pode ser representada (DESCARTES, 1999a, p. 131.).

Analisando essa passagem da obra cartesiana, nos parece evidenciar uma certa busca da alma pelo corpóreo, ou seja, a alma quando é necessário conhecer, lembrar ou pesquisar sobre as coisas sensíveis, utiliza da imaginação como instrumento criador de imagens.

\section{Imaginação Produtiva e a Geometria}


Enfim, o que a análise do tratamento do conceito de imaginação nas obras metafísicas de Descartes nos revelou foi um certo conservadorismo do autor, não introduzindo nele, aparentemente, nada de muito novo em relação a tradição, mas o trata exatamente como já era comum desde a antiguidade. Segundo Christophe Bouriau:

\begin{abstract}
Para os escritores da escola de Aristóteles, os produtos da imaginação têm sempre um ar de déjà $v u$, já que essa faculdade funciona sempre a partir de sensações ou "espécies sensíveis" que já se apresentaram. Considera-se então que teriam os comentadores de Aristóteles contribuído para a formação intelectual de Descartes com três sentidos do termo imaginação: 1) a imaginação como um lugar cerebral que preserva as sensações, 2) a imaginação como a faculdade reprodutiva da alma que apresenta por essas sensações as coisas em sua ausência, 3) a imaginação como uma potência plástica que divide e compõe sensações. (BOURIAU, 2000, p. 77, tradução nossa.).
\end{abstract}

Ou seja, Descartes recebe da herança Aristotélica um conceito de imaginação com alicerce já sedimentado, segundo o qual a imaginação pode ser considerada como: um lugar físico em nosso cérebro, a fantasia ${ }^{8}$; se identifica também como uma "capacidade" de reprodução da matéria dos nossos sentidos; e uma força ativa, exercida pela alma, que lhe permite fazer alterações, composições ou decomposições das sensações retidas em nossa fantasia.

Todavia, Descartes, segundo Bouriau, foi o responsável por acrescentar mais uma característica a essa faculdade. Sob uma grande influência do neoplatônico Proclus, Descartes irá estabelecê-la ainda como uma "capacidade" de produção da mente, além daquela de simples reprodução, herdada dos aristotélicos. Deste modo, há em Descartes uma noção de imaginação produtiva ${ }^{9}$, que podemos nomear também como intelecto figurativo. Essa "capacidade" da imaginação, segundo Descartes, é a que permite ao nosso pensamento trabalhar com as figuras geométricas, dizendo melhor, estabelecer figuras correspondentes às

\footnotetext{
${ }^{8}$ Ver $12^{\circ}$ Régra, DESCARTES, René, 1596-1650. Regras para orientação do espírito. Descartes; tradução Maria Ermantina Galvão. - São Paulo: Martins Fontes, 1999.

${ }^{9}$ Utilizo como base de minha argumentação na teoria da imaginação como faculdade criadora de imagens geométricas, ou seja, imaginação produtiva, a obra BOURIAU, Christophe. Aspects de la finitude: Descartes et Kant. Bordeaux: Presses universitaires de Bordeaux, 2000. Christophe Bouriau tem como suas principais obras estudos voltados a Descartes e principalmente Kant. Seu doutorado, sob orientação de Jean-Luc Marion, teve como pesquisa: a função crítica da sensibilidade em Descartes e Kant. Possui alguns livros com o tema principal a imaginação, onde faz algumas comparações sobre esse tema em comum nos dois autores, e de certo modo os aproxima. Devido ao intuito do autor de fazer uma comparação e aproximação da teoria dos dois autores, nota-se que o vocabulário utilizado pelo mesmo em sua obra é por vezes confuso, uma mescla entre cartesianismo e kantismo. Deste modo, o autor define conceitos centrais da teoria cartesiana sobre a imaginação através de termos kantianos, como: "imaginação reprodutiva", "imaginação produtiva", "intelecto puro", a "priori". Decidi preservar os termos utilizados por Bouriau, mesmo sabendo do comprometimento que eles haviam com uma teoria kantiana, porém, acredito que tais termos são por hora, os melhores para explicar as especificidades deste tipo de pensamento na teoria cartesiana. Portanto, o leitor terá de ter claro que apesar de os termos utilizados tanto na obra de Bouriau, quanto em meu artigo pretendem facilitar o entendimento do leitor para a distinção que pode ser feita nesse conceito em Descartes, que de certo modo, antecipa a mesma distinção feita por Kant.
} 
verdades divinas da matemática, revelando-a, por isso, como uma faculdade do conhecimento intermediário entre o intelecto e a sensibilidade.

O que seria essa imaginação produtiva? A imaginação produtiva seria a capacidade que a faculdade imaginativa tem em produzir ideias ou imagens totalmente novas, sem que tenha alguma sensação como elemento constitutivo dessa imagem. Diferente da composição de imagens que já nos é ocorrente, quando ativamente a imaginação mistura imagens e ideias de diferentes coisas para formar quimeras, por exemplo.

A imaginação produtiva de Descartes produz sem reproduzir e isso porque ela, sobretudo na geometria, trabalha somente a partir da extensão pura, simples. Vimos nas meditações a extensão sendo tratada como res extensa. Essa natureza, como veremos a seguir é uma natureza simples ${ }^{10}$, ou seja, como um dado a priori do espírito. Elas estão no grupo das ideias inatas, realidades que não podem ser encontradas por meio da sensação, pois são inerentes a nossa alma. Nós não podemos procurar estas noções simples em outros lugares a não ser em nós mesmos. No caso específico da geometria, a imaginação se desloca, em certa medida, dos corpos, pois é através da noção de extensão pura e simples que ela figura e representa materialmente as coisas da geometria. Cito uma passagem de Christophe Bouriau:

\begin{abstract}
A imaginação trabalha a partir da extensão concebida como simples ou pura, para cortar figuras, compor os pontos e as linhas, não precisa mais reproduzir ou combinar sensações. Ela não reproduz o que a alma já viu, mas faz ver pela primeira vez, o que sem ela, permaneceria invisível. Em suma, produz a figura das coisas. (BOURIAU, 2000, p. 80, tradução nossa.)
\end{abstract}

Essa importante característica da faculdade imaginativa, a capacidade de produzir figuras geométricas, aparece como uma novidade nas teorias do conhecimento modernas. Ademais, ainda que essa capacidade de figuração se mostre sumamente importante para a sua Mathesis Universalis, não encontramos em nenhum momento em sua principal obra dedicada exclusicamente a essa ciência, A Geometria, uma designação de que essa tarefa fosse destinada para a faculdade imaginativa11. Se tomamos A Geometria como material depesquisa sobre esta função da imaginação, notamos que Descartes enquanto mencionando ou evocando uma figura geométrica, quase sempre utilizao verbo imaginar, de forma corriqueira, como se já nos fosse clara essa relação, citamos alguns exemplos: "[...] se eu quiser saber de qual gênero é a linha EC, a qual imagino[...]” (DESCARTES, 2018, p. 387); “

${ }^{10}$ Cf. SOARES, Alexandre Guimarães. A emergência da terceira noção primitiva na correspondência com Elisabeth. Modernos \& Contemporâneos, Campinas, v. 1, n. 2, p. 130-146, dez. 2018.

${ }^{11}$ Podemos creditar esse fato pelo interesse específico que esta obra possui. A Geometria, como também os outros dois ensaios, A Dióptrica e Os Meteoros, que foram publicados juntamente com a edição original francesa do Discurso do método, possuía um objetivo demonstrativo, ou seja, de demonstrar na prática o seu método analítico, estabelecido pelo texto introdutório da obra completa, $O$ Discurso. Na Geometria, Descartes não nos oferece um ensaio propriamente epistemológico, preocupado com sua fundamentação teórica sobre o intelecto humano, mas, sim em um ensaio técnico, dedicado a aplicar seu método analítico, neste caso, especificamente na geometria, resolvendo antigos problemas matemáticos. 
E de qualquer outra maneira que se imagino a descrição de uma linha curva"[...] (DESCARTES, 2018, p. 389);

[...] e considerando a geometria como uma ciência que ensina a conhecer gerelamente as medidas de todos os corpos, não se devem excluir as linhas mais compostas nen as mais simples, desde que se possa imaginá-las serem descritas por um movimento contínuo[...] (DESCARTES, 2018, p. 382).

Percebe-se que na Geometria, Descartes não está preocupado em explicar as causas epsitemológicas da geometria, mas simplesmenteem sua função prática. Entretanto, em suas obras com um caráter espistemológico, como as Regras e as Meditações, nos é possível enxergar melhor essa relação entre a faculdade da imaginação e a ciência da ordem e medição cartesiana, a Mathesis Universalis.

Vemos na sexta meditação: "Se se trata, em verdade, de um pentágono, posso sem dúvida entender sua figura [...] sem a ajuda da imaginação, mas posso também imaginá-la, isto é, aplicar a ponta da mente a seus cinco lados e, ao memso tempo, à área que eles contêm.” (DESCARTES, 2004, p. 157). Neste momento do texto, Descartes está distinguindo intelecção pura de imaginação, nos confirmando que podemos entender as leis matemáticas pelo intelcto puro, mas, além disso, podemos também utilizar a imaginação para criarmos as figuras que possibilitam calcular a área que determinada extensão possui. Nas Régras vemos: "A mesma regra deve ser aplicada à extensão real dos corpos e proposta por inteiro a imaginação com a ajuda de figuras puras e simples: assim, de fato, ela será compreendida com muito mais clareza pelo entendimento." (DESCARTES, 1999b, p. 107). Aqui, após já ter explicado como podemos representar em nosso cérebro as figuras das coisas exterioeres, que são percebidas pelos sentidos externos e pintadas pela imaginação em nosso cérebro, possibilitando a visão sobre as coisas exteriores que nossa alma enxerga, Descartes nos introduz como podemos, através da geometria, calcular e matematizar os corpos extensos. Através de figuras simples e puras, ou seja, das figuras geométricas, por suposição e comparação com aquelas reais e extensas, se torna possível colocar em prática a Mathesis Universalis, ou seja, o poder de calcular pela matemática todo e qualquer tipo de extensão do mundo material.

\footnotetext{
No que diz respeito às figuras, já foi mostrado mais acima como é apenas por elas que se podem formar ideias de todas as coisas (extensas) [...] (DESCARTES, 1999b, p. 121-22)
}

Depois dessas observações [...] Não se deve guardar nenhuma para o nosso uso, salvo as superfícies retilíneas e retangulares, ou então as linhas retas, que chamamos também de figuras, pois elas não nos servem menos do que as superfícies para imaginar um sujeito realmente extenso, como foi dito mais acima. (DESCARTES, 1999b, p. 124)

Deste modo, vemos que a imaginação não reproduz, mas produz uma ideia totalmente nova, partindo para isso da intuição pura da figura, intuição que sem a imaginação 
permaneceria apenas umas intuição invisível, ou seja, algo apenas intuído pelo intelecto puro, porém, sem a sua exibição figurativa, ausente aos "olhos de meu espírito" (DESCARTES, 2004, p. 157-159). É graças à “capacidade” produtiva da imaginação que podemos, segundo Descartes, criar as figuras geométricas. Descartes dá à imaginação o poder de desenhar linhas e formá-las mentalmente, "lineolasducere et formare in cerebro" (Entretien avec Burman, AT V 163 Apud (BOURIAU, 2000, p. 81). Podemos dizer que a imaginação produtiva possui esse poder: trazer à tona, nos mostrar, nos exibir, tudo aquilo que é inicialmente invisível:

\footnotetext{
Com Descartes, a imaginação não reproduz o já visto, mas tira a coisa de sua invisibilidade, traz para fora das sombras, os "desinibidos", pode-se dizer: é nesse sentido um poder de exhibitio. A imaginação, escreve Descartes muitas vezes, exibe conceitos matemáticos por meio de figuras. (BOURIAU, 1999, p. 82, tradução nossa.)
}

Esse poder de dar imagens às coisas invisíveis do intelecto puro, que Descartes acrescenta à imaginação, adquire grande importância para seu projeto da Mathesis Universalis (ciência da ordem e da medição), já que é através dela nós podemos aplicar os conceitos da matemática pura no mundo físico: calcular e fazer ciência do mundo das coisas extensas, mediante figuras imagináveis por nossa fantasia. Para Descartes, todas as coisas sensíveis que podem ser figuradas, deste modo, poderão também ser mensuradas. É a imaginação produtiva que assegura a aplicação da Matemática à Física. Como escreve J.-L. Marion, graças à imaginação, "dimensões não espaciais podem ser transcritas em figuras, que as tornam mensuráveis” (MARION, 1996, p.309, tradução nossa.)

\section{Conclusão:}

Portanto, pretendíamos demonstrar uma dualidade na maneira de apreciação da faculdade imaginativa na teoria cartesiana. Expusemos primeiramente o famoso dualismo cartesiano, que é causa essencial para as ditas faculdades híbridas, ou seja, a imaginação e a sensação. Percebemos também, que a imaginação, apesar de ser considerada um tipo de pensamento ativo, ou seja, feito pela alma, no ramo da Metafísica, dos conhecimentos puros, diferentemente da sensação, era considerada uma forma do pensar, um tanto inadequada, pois, é composta por figura e extensão, ou seja, res extensa, e para conhecimentos puros como a Metafísica somente as intuições puras do intelecto são passíveis de certeza. Ademais, a imaginação possui um papel secundário nesse tipo de conhecimento. Secundário, mas não menos importante, Descartes a utiliza como um instrumento para a dúvida metódica e de certo modo como argumento para a existência de nosso próprio corpo, como vimos em Gueroult. 
Porém, em suas obras físicas, Descartes já nos evidencia algumas características da faculdade imaginativa com significante importância para seu projeto de Mathesis Universalis. A partir dessas obras, e já no final das Meditações, podemos notar que a faculdade imaginativa além de possuir um caráter ativo, ou seja, ser uma ação da alma, é também uma importante faculdade para a criação de figuras geométricas, utilizando da extensão pura e simples e das verdades matemáticas inatas, como instrumento das ciências físicas. A geometria, que é uma ciência construída através da imaginação, seria uma ciência intuitiva, ou seja, totalmente inspecionada pela razão, pois apesar de ser criada a partir da imaginação as imagens geométricas são construídas em uma extensão destituída de sensações, inteiramente pura, onde as imagens seriam criadas e não compostas pela imaginação. É pela natureza simples da extensão pura, que as figuras geométricas podem ser inspecionadas pela razão, pois a razão só pode intuir naturezas simples. Com isso, a imaginação passa a ser uma faculdade não só ativa, mas também produtora, pois as imagens geométricas são produzidas por ela ${ }^{12}$.

Enfim, o que conseguimos identificar com essa breve pesquisa sobre esse modo de pensamento na teoria cartesiana é que quando nós pretendemos estudar e pesquisar as coisas exteriores a nós, ou seja, as coisas materiais, nossa alma utiliza de todos as suas potências para melhor as conceber. Até porque, nossa alma possui a característica da imaterialidade, e seria impossível ela entrar em contato com as coisas materiais, sendo assim, dependente da união substancial para viver em contato com o mundo material. Como o próprio René Descartes nos disse:

\footnotetext{
Daí se conclui com certeza que, se o entendimento se ocupa com o que nada tem de corporal ou de semelhante ao corporal, ele não pode ser ajudado pelas faculdades de que acabamos de falar, mas, ao contrário, para que nelas não encontre nenhum empecilho, cumpre afastar os sentidos e despojar tanto quanto o possível a imaginação de qualquer impressão distinta. Se, de outro lado, o entendimento se propõe a examinar um objeto que pode ser relacionado com u corpo, é a ideia de objeto que se deve formar o mais distintamente possível na imaginação; para fazê-lo com mais comodidade, deve-se mostrar aos sentidos externos o próprio objeto que essa ideia representará. (DESCARTES, 1999b, p. 81).
}

\section{Referências:}

12 Cf. SOARES, Alexandre Guimarães. A emergência da terceira noção primitiva na correspondência com Elisabeth. Modernos \& Contemporâneos, Campinas, v. 1, n. 2, p. 130-146, dez. 2018. Neste artigo Alexandre Soares demonstra como se dão as três noções primitivas, e como cada uma delas possui uma maneira específica de ser estudada, uma cadeia própria de relações. A noção primitiva da extensão, ou seja, a res extensa, é a noção de caráter material, portanto, imaginável e figurada, deste modo, dependente da imaginação para ser trabalhada. 
ANDRADE, Érico. Hipótese e Experiência na Constituição da Certeza Científica em Descartes. Cadernos de História e Filosofia da Ciência, Campinas, v. 16, n. 2, p. 259-280, dez. 2006.

BOURIAU, Christophe. Aspects de la finitude: Descartes et Kant. Bordeaux: Presses universitaires de Bordeaux, 2000.

COTTINGHAN, John. Dicionário Descartes; tradução, Helena Martins; revisão técnica, Ethel Alvarenga; consultoria, Raul Landim - Rio de Janeiro: Jorge Zahar Ed., 1995.

DESCARTES, René. Discurso do método, As paixões da alma e Meditações. Tradução brasileira de J Guinsburg. São Paulo: Editora Nova Cultural, 1999a.

. Discurso do método e Ensaios / René Descartes; organizado por Pablo Rubén Mariconda; traduzido por César Augusto Battisti, Érico Andrade, Guilherme Rodrigues Neto, Marisa Carneiro de Oliveira Franco Donatelli, Pablo Rubén Mariconda, Paulo Tadeu da Silva. - São Paulo: Editora Unesp, 2018

. Meditações sobre Filosofia Primeira/ Descartes; tradução: Fausto Castilho. - Ed. Bilingue em latim e português - Campinas, SP: Editora da Unicamp, 2004.

. Oeuvres: correspondance. Publièes par Charles Adam e Paul Tannery. Vol. III. Paris: LibrairiePhilosophique J. Vrin, 1996.

. Oeuvres: correspondance. Publièes par Charles Adam e Paul Tannery. Vol. V. Paris: LéopoldCerf, 1903.

Oeuvres: correspondance. Publièes par Charles Adam e Paul Tannery. Vol. III. Paris: LéopoldCerf, 1903.

$O$ mundo (ou tratado da Luz) e $O$ Homem/ René Descartes; apresentação, apêndices, tradução e notas: César Augusto Batistti e Marisa Carneiro de Oliveira Franco Donatelli. - Campinas, SP: Editora da Unicamp, 2009.

. Regras para orientação do espírito. Descartes; tradução Maria Ermantina Galvão. - São Paulo: Martins Fontes, 1999b.

GUENANCIA, Pierre. L'Intelligence du sensible. Essai sur le dualisme cartésien. Paris:

Gallimard, 1998.

GUEROULT, Martial. Descartes segundo a ordem das razões. Tradução brasileira de Érico Andrade, Enéias Forlin, Alexandre Soares, César Battisti, Marisa Donatelli. São Paulo: Discurso Editorial, 2016.

MARION, J.- L., Questions Cartésiennes II. Surl'ego et sur Dieu, Paris, PUF, Epiméthée, 1996.

SARTE, Jean-Paul. A Imaginação. Tradução brasileira de Luiz Roberto salinas Fortes. São Paulo: Difusão Europeia do Livro, 1967

SOARES, Alexandre Guimarães. A emergência da terceira noção primitiva na correspondência com Elisabeth. Modernos \& Contemporâneos, Campinas, v. 1, n. 2, p. 130-146, dez. 2018. 